\title{
CULTURA IMATERIAL: MITOS E LENDAS DE BELÉM-PA
}

\section{Glauce Vitor da SILVA \\ PPGCA/UEPA \\ glaucevitor@yahoo.com.br}

Resumo: O trabalho intitulado "Cultura Imaterial: Mitos e Lendas de Belém" tem como objetivo a análise e a compreensão das lendas e mitos de Belém, que permeiam o imaginário da população da cidade. Para, a partir disso, verificar a possibilidade de potencializar esses elementos culturais como forma de valorização e de reafirmação da identidade local. Este trabalho foi desenvolvido metodologicamente por meio de pesquisa de campo, com a observação direta e roteiros de entrevistas, além de pesquisas bibliográficas. As entrevistas foram realizadas no período de dezembro de 2008 a janeiro de 2009. Foram escolhidos os bairros do Umarizal e da Pedreira por apresentarem moradores com características de vivências, situações financeiras e crenças diferentes. As entrevistas foram realizadas com o intuito de verificar o conhecimento dos habitantes da cidade de Belém sobre as histórias, e observar quais narrativas são as mais conhecidas entre os moradores.

Palavras-chave: Lendas e Mitos. Cultura Imaterial. Identidade Local.

Abstract: The paper called "Immaterial culture: Myths and legends of Belém-Pa" has as goal, analyze and comprehend the stories that live in the imagination of people that born and live in Belém. Then, verifying the possibility of potencialize those culture elements as way to value and re-establish the local identity. This paper was developed methodologically by field research, with a direct look and interview scripts, beside bibliographic research.The interviews were conducted betwenn december 2008 e january 2009. The districts of Umarizal and Pedreira were chosen for presenting residents with diferent characteristics of experiences, financial situations and beliefs. The interviews were conducted in order to verifiey the knowledge of the habitants of Belém about the stories, and observe wich narratives are most popular among them.

Keywords: Legends and myths. Immaterial culture. Local identity.

\section{9}




\section{Introdução}

O Pará é o segundo maior estado do Brasil em extensão territorial, e, nos seus quatro cantos, é possível escutar os mitos e lendas narradas e passadas às gerações seguintes e conviver com eles. Essas novas gerações ajudam a conhecer e a construir a cultura local, além de explicar, aos olhos desses povos, um pouco da história deles. E, na própria capital do Estado, acreditava-se que fatos sobrenaturais verdadeiramente aconteciam, e, durante anos, as histórias fantásticas assombraram as ruas de Belém.

Essas histórias de visagens e assombrações e lendas urbanas, como a da "A moça do Táxi" e a da "Matinta Perera", contada há anos de gerações para gerações, estão incluídas no contexto de lendas, por misturar, segundo Eliade (1972), fatos reais com o fantástico. Em contrapartida, a história da "Cobra-grande", que para muitos ribeirinhos é a explicação para o surgimento de alguns dos grandes rios da região amazônica, enquadra-se como mito, por ser uma história fantasiosa que tenta explicar como algo passou a existir.

Os mitos e as lendas fazem parte do rico folclore amazônico, assim como as músicas populares, a poesia e as danças, que encantam e fazem parte do imaginário dos habitantes da região. As lendas e mitos são narrativas e histórias que fazem parte da cultura imaterial do povo paraense, que segundo os autores Marconi e Presotto:

Refere-se a elementos intangíveis da cultura, que não têm substância material. Entre eles encontram-se crenças, conhecimentos, aptidões, hábitos, significados, normas, valores. Os membros de uma sociedade compartilham certos conhecimentos e crenças como reais e verdadeiros (MARCONI; PRESOTTO, 2006, p. 26).

Grande parte das lendas e mitos da cidade de Belém pode ser dividida entre histórias de visagens e assombrações. De acordo com o Dicionário Aurélio (1995), visagem significa "fantasma"; já assombração significa "Pavor motivado pelo encontro ou aparição imaginária de coisas sobrenaturais".

\section{1 Área de pesquisa}

A escolha dos bairros Umarizal e Pedreira para a realização da pesquisa derivou das diferenças existentes entre eles. O primeiro é 
considerado um bairro novo, de classe média, mas que, no que concerne ao tema desta pesquisa, foi considerado um bairro com menos riqueza de histórias e mitos, se comparado ao bairro da Pedreira, um dos mais antigos de Belém.

O bairro do Umarizal é um notório reduto de intelectuais, boêmios e sambistas. Neste, nasceram e viveram conhecidos artistas e intelectuais paraenses, como o escritor Raymundo Mário Sobral, a jornalista e escritora Eneida de Moraes e o sambista e compositor David Miguel.

As ruas e travessas do Umarizal marcam importantes momentos da nossa história, e tiveram seus nomes oriundos de personagens do nosso passado, como afirma Cruz (1992):

[...] o bairro do Umarizal lembra a epopéia das lutas nacionalista, em que se notabilizaram João Balbi, Boaventura da Silva, Domingos Marreiros, Antônio Barrreto, Diogo Móia, Oliveira Belo, Bernal do Couto, onde estiveram envolvidos também, dois ilustres cametaenses - os Bispos dom Romualdo Coelho e dom Romualdo de Seixas, este último, por sinal, titular do Império e Primaz da Bahia. Todos têm os seus nomes gravados nas placas das ruas e travessas daquele bairro (CRUZ, 1992, p. 20).

Durante a realização da pesquisa de campo, foi possível observar que a população residente do bairro do Umarizal apresenta uma grande parcela de moradores idosos, mantendo, desta forma, características tradicionais semelhantes às interioranas.

Embora o bairro do Umarizal tenha apresentado e ainda apresenta um grande crescimento vertical, é ainda possível encontrar nas suas ruas e travessas, um grande número de residências tradicionais, como é o caso da casa da informante Maria Auxiliadora, moradora há 50 anos no bairro.

Ali, é comum se deparar com residentes mais velhos, sentados na frente de suas casas e conversando com seus vizinhos nos fins das tardes. E foi justamente entre esses residentes que se concentrou a maior parte de nossos informantes. Pessoas que ainda têm o saber tradicional, conhecendo ainda as poucas lendas, mitos e histórias de visagens e assombrações que lá encontramos, as quais lhes foram contadas por seus familiares e amigos durante sua infância ou juventude.

Verificamos, ainda, que os informantes mais idosos têm interesse de repassar essas histórias, essa parcela da sua cultura, não somente para 
seus familiares, mas também para qualquer curioso que queira conhecer um pouco deste saber tradicional.

Tal como no bairro do Umarizal, no da Pedreira observamos um grande número de pessoas mais velhas, justificando, dessa forma, o saber tradicional concentrado ali.

O bairro da Pedreira também é caracterizado por pessoas alegres e festeiras, sendo conhecido também como o bairro do Samba e do Amor. A moradora Nara Núbia de Souza explica com a seguinte afirmação:

Antigamente, o bairro era o principal quando se falava de carnaval. A escola de samba era a mais forte quando ia pra competição, e o bairro todo se preparava pra curtir o carnaval. Ee eu acho que ficou conhecido como o do amor também, porque era no carnaval que muitos romances começavam.

A Pedreira concentra Barracões das duas das escolas mais tradicionais de Belém, a Império Pedreirense e a Acadêmicos do Samba da Pedreira. E ainda abriga a Aldeia Cabana, atual Aldeia de Cultura Amazônica Davi Miguel, o Sambódromo de Belém, que serve como Palco para vários eventos culturais da Cidade.

Este é também, considerado um dos bairros mais ricos em histórias de mitos e lendas da cidade de Belém. No livro Visagens e Assombrações de Belém, de Walcyr Monteiro, o bairro da Pedreira é um dos principais protagonistas de relatos dessas histórias. E foi lá onde recolhemos os relatos das histórias mais conhecidas entre os moradores de Belém, como a da "Matinta Perera da Pedreira", a qual conta a história de uma Sra. que virava Matinta Perera:

E, certa noite... Guapindaia ainda guarda na memória o ocorrido... quando atravessou a encruzilhada que delimitava os quintais, ouviu o assobio da Matinta Perera, que vinha do lado da esquina do Chaco com a Marquês de Herval. Firifififiuиuи...!

E o assobio veio aumentando de intensidade. Firifififiuuuu...!

Aumentou... aumentou... aumentou... até tornar-se forte $e$ estridente. - Firifififiuumu...!

Guapindaia ficou paralisado. E sentiu por sobre sua cabeça o farfalhar de asas, tal como um pequeno tufão, movimentando 
as folhas das árvores próximas pelo deslocamento de ar provocado.

Guapindaia, pregado ao solo como se raizes tivesse criado, viu o estranho pássaro tomar o rumo do quintal da Velha Mariana...

Pouco depois, as luzes da casa da benzedeira acenderam-se, e surge Velha Mariana, penteando-se e olhando tristemente para a lua, cuja luz espraiava-se pelo velho bairro da Pedreira... (MONTEIRO, 2000, p. 48).

Monteiro (2000) narra ainda em sua obra "Os gritos dos lenhadores da Pedreira", história atualmente pouco lembrada pelos moradores do bairro, que fala de um lenhador que, há cerca de 230 anos, encontrara um ladrão roubando sua lenha. Este matou o ladrão larápio. Mais tarde, em outro duelo, foi morto. E desde então o espírito daquele que ele matara vivia perseguindo-o, a fim de vingar-se.

\section{$2 \mathrm{O}$ folclore como elemento representativo da cultura belenense}

A identidade é o sentido que temos de que algo nos pertence, de algo que forma o que somos. Martins (2003, p. 42) afirma que identidade seria "esse sentido de pertencer que as pessoas trazem enquanto seres simbólicos que são. Esse ser de algum lugar pertence a algum grupo, sente afinidade com algo que lhe resgata algo seu; isto tudo é chamado de identidade"

De acordo com Banducci Jr. e Barreto (2001), a identidade apresenta características de algo em constante mobilidade, que está sempre em construção, e que dessa forma vai se moldando por meio de contato com outro indivíduo. Quando esse contato ocorre entre o novo e o tradicional, a cultura de ambos se fortalece.

Um dos principais embates entre diversos autores é acerca do surgimento da cultura, sobre como o ser humano começou a ter ciência de algo que o diferenciava não somente dos animais, mas também de outras pessoas, outros povos, grupos e de outras sociedades.

O antropólogo Levi-Strauss acredita que a cultura surgiu no momento em que o ser humano criou a sua primeira regra, a qual ele 
acredita que seja sobre a proibição do incesto. Considerando, então, que esta regra tenha sido o momento que surgiu a cultura, vamos analisar o próprio termo.

De acordo com Laraia (1997), existia uma expressão germânica chamada Kultur, a qual era empregada para representar os aspectos espirituais de uma comunidade, bem como um termo francês chamado Civilisation, que aludia às concretizações materiais de um povo. Em 1871, Edward Tylor uniu os dois termos e sintetizou-os em um termo inglês intitulado de Culture, definindo-o da seguinte forma:

Tomado em seu amplo sentido etnológico é este todo complexo que inclui conhecimentos, crenças, arte, moral, leis, costumes ou qualquer outra capacidade ou hábitos adquiridos pelo homem como membro de uma sociedade (TYLOR Apud LARAIA, 1997, p. 25).

A concepção que hoje temos de cultura foi proveniente de E. Tylor, que foi trabalhada e aprimorada por diversos autores no decorrer dos séculos. Santos (1994, p. 44) define a cultura "como uma dimensão do processo social, da vida de uma sociedade".

Nesse sentido, a cultura de um homem é proveniente do contato com outros grupos, da herança cultural passada de geração em geração. A cultura de uma pessoa, então, não deriva somente de um individuo, mas sim de todo uma coletividade. Como diz Laraia (1997, p. 46) "O homem é o resultado do meio cultural em que foi socializado".

Nessa perspectiva, a cultura de cada ser é resultado de vários contatos sociais, de aprendizados, sejam eles na escola ou na rua, e, principalmente, do conhecimento que os pais passam para os filhos. $\mathrm{O}$ ser humano, por sua vez, absorve tudo que the foi passado dos diferentes contatos, e sintetiza tudo, criando, desta forma, a sua própria cultura, as suas próprias crenças.

Pode-se dizer, então, que a cultura de um indivíduo nunca é derivada de apenas um contato social, visto que, se fosse desta forma, todas as pessoas teriam as mesmas crenças, os mesmos conhecimentos e os mesmos valores. E, por sua vez, a civilização não chegaria a progredir, pois se teria hoje os mesmos valores de gerações passadas; não se introduziria 
nada de novo nos conhecimentos já existentes. Santos explica o processo de construção da cultura da seguinte forma:

[...] cultura diz respeito a todos os aspectos da vida social, $e$ não se pode dizer que ela exista em alguns contextos e não em outros.

Cultura é uma construção histórica, seja como concepção, seja como dimensão do processo social. Ou seja, a cultura não é algo natural, não é uma decorrência de leis físicas ou biológicas. Ao contrário, a cultura é um produto coletivo da vida humana (SANTOS, 1994, p. 44).

As divergências existentes hoje na sociedade são justamente provenientes das distintas culturas, já que cada ser humano observa o mundo, a sociedade por meio da sua própria cultura, ou seja, cada um acredita que a sua forma de viver, os seus valores, seus conhecimentos, e até mesmo a sua fé, são os mais corretos e os mais apropriados. Aliandose a isso a baixa tolerância do ser humano em aceitar e respeitar as culturas distintas, diversos conflitos acabam por acontecer. Essa afirmativa é justificada por Larraia, quando afirma:

O fato de que o homem vê o mundo através de sua cultura tem como consequência a propensão em considerar o seu modo de vida como o mais correto e o mais natural. Tal tendência, denominada de etnocentrismo, é responsável em seus casos extremos pela ocorrência de numerosos conflitos sociais (LARRAIA, 1997, p. 75).

Atualmente podemos separar a cultura, em duas concepções básicas. De acordo com Santos:

A primeira dessas concepções preocupa-se com todos os aspectos de uma realidade social. Assim, cultura diz respeito a tudo aquilo que caracteriza a existência social de um povo ou nação, ou então de grupos no interior de uma sociedade. [...] cultura refere-se a realidades sociais bem distintas. No entanto, o sentido em que se fala de cultura é o mesmo: em cada caso dar conta das características dos agrupamentos a que se refere, preocupando-se com a totalidade dessas características dos agrupamentos a que se refere, digam elas 
a respeito [das] maneiras de conceber e organizar a vida social ou [dos] seus aspectos materiais. [...] Mas eu disse que havia duas concepções básicas de cultura. Vamos à segunda. Neste caso, quando falamos em cultura estamos nos referindo mais especificamente ao conhecimento, às idéias e crenças, assim como às maneiras como eles existem na vida social. Observem que mesmo aqui a referência à totalidade de características de uma realidade social está presente, já que não se pode falar em conhecimento, idéias, crenças sem pensar na sociedade à qual se referem. O que ocorre é que há uma ênfase especial no conhecimento e dimensões associadas. Entendemos neste caso que a cultura diz respeito a uma esfera, a um domínio, da vida social (SANTOS, 1994, p. 24).

Desta forma, após analisar as concepções básicas de Santos (1994), pode-se dividir a cultura em dois grupos: o da cultura material e o da cultura imaterial. A cultura material se refere ao que é concreto, ou seja, aos bens culturais, que englobam objetos, artefatos e construções. Enquanto que a imaterial se refere ao que é abstrato, como as cantigas, as lendas, os mitos e as histórias de visagens e assombração.

A cultura imaterial contempla desde o aprendizado de como caçar, pescar, empinar uma pipa até a maneira de aprender as brincadeiras na infância. E, é neste grupo, da cultura não tangível que a nossa pesquisa se focaliza.

Esta cultura faz alusão, como já mencionado, ao não concreto, no caso, os aprendizados, conhecimentos de uma pessoa, grupo ou sociedade. As lendas e mitos de Belém - objeto de estudo deste trabalho são umas das melhores traduções do saber e da criatividade popular, visto que as histórias de visagens e assombrações de Belém abrangem misturas da realidade com fatos fantasiosos, os quais são reais para grande parte da população.

Estas histórias são manifestações do folclore belenense. De acordo com Brandão, folclore pode ser definido da seguinte maneira:

Na cabeça de alguns, folclore é tudo o que o homem, o povo faz e reproduz como tradição. Na de outros, é só uma pequena parte das tradições populares [...]. O folclore vive da coletivização anônima do que se cria, conhece e reproduz, 
ainda que durante algum tempo os autores possam ser

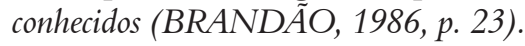

Entretanto, para muitos autores, folclore e cultura popular têm o mesmo significado. Cascudo (apud BRANDÃO, 1986, p. 24) define folclore como sendo "a cultura do popular tornada normativa pela tradição".

Ambas as definições de folclore, a de Brandão e a de Cascudo, remete-nos às tradições populares. Desta forma, podemos afirmar que as lendas, mitos, visagens e assombrações são tradições populares, as quais vão se reproduzindo através dos anos.

\section{Lendas e mitos da cidade de Belém/PA: cultura imaterial de nosso povo}

Belém é uma cidade rica em cultura, com seus sabores, cheiros e cores, os quais podem ser encontrados em cada esquina: nas lendas e mitos contadas, no carimbó, nas vendas do cheiro do Pará no Verô-Peso, nas barracas de tacacá, nas vendas de açaí anunciadas com bandeirinhas vermelhas, nas mangas que caem das mangueiras, entre outros. São particularidades da comida regional, frutos da natureza pródiga, da colonização portuguesa e das heranças indígena e africana. E é essa miscigenação cultural e racial que se faz presente igualmente no artesanato e no rico folclore, representado aqui pelas lendas e mitos.

Estas lendas e mitos são um dos maiores exemplos da cultura imaterial representada na cidade de Belém, muitos provenientes dos interioranos do estado do Pará, os quais trouxeram essas histórias para a capital e transmitiram esses conhecimentos ao povo da capital. Presentemente, fazem parte da crença não somente dos interioranos, mas também da população belenense. Tocantins relata como ocorreu a transmissão destas histórias:

Belém, cidade civilize, não escapa à fascinação do sobrenatural. Não há menino que deixe de ouvir estórias fantásticas, transmitidas pelas amas, empregadas domésticas, geralmente pessoas vindas do interior do Estado, onde sobrevive, intensa, a tradição oral dessas lendas. Mesmo sob o impacto de outros valores culturais que hoje se manifestam 
na cidade, consequência da aproximação no espaço geográfico e no tempo social com povo e instituições, aproximação efetuada pelo avião, o rádio, a televisão, o jornal - ainda persistem as estórias sobrenaturais na mente do povo. (TOCANTINS apud MONTEIRO, 2000, p. 13).

As diferenças das lendas e dos mitos de Belém narradas por Monteiro (2000) para a forma oral relatada pelos entrevistados dos bairros da Pedreira e Umarizal da cidade de Belém mostram a constante modificação e evolução cultural das histórias, bem como uma característica essencial da cultura, a da constante mutação, como explicado anteriormente.

As histórias relatadas pelos moradores dos dois bairros utilizados para essa pesquisa mantiveram relatos semelhantes, e em ambos os bairros a história mais conhecida e a mais "contada" foi a da "Moça do Táxi", entretanto, com algumas diferenças da narrada no livro de Monteiro (2000).

A história "A moça do táxi" é uma narrativa sobre uma moça chamada Josephina Conte, a qual morava na cidade de Belém (existem várias divergências sobre o endereço) e que todo ano, no dia do seu aniversário, o seu pai pagava um passeio de táxi pela cidade de Belém, e ela sempre dizia ao taxista que recebesse o dinheiro do passeio no dia seguinte, na casa do pai dela.

"A moça do táxi" conta, ainda, que após o falecimento da moça, ela continuou a fazer o passeio todo ano, no dia do seu aniversário. E no dia seguinte, quando o taxista ia receber pelo passeio que havia dito, os pais de Josephina lhe diziam que a moça já havia falecido.

$\mathrm{Na}$ cidade de Belém, conta-se que essa história acontece até nos dias de hoje, todo ano. A moça Josephina Conte está enterrada no cemitério de Santa Izabel, cujo túmulo contém um retrato dela, trajando um vestido no qual há um broche em forma de carro, o que, para muitos, é um táxi, e serve para mostrar a paixão da moça pelos passeios de táxi que fazia. Atualmente, ela é considerada uma espécie de "santa" pela população belenense, e muitos acorrem a ela por acreditarem que seja capaz de realizar milagres. Josephina Conte é cultuada às segundasfeiras, no cemitério de Santa Izabel.

Em muitos relatos, como o de Jorge Barroso, de 23 anos, morador do bairro do Umarizal há 13 anos, consta que o taxista cobrava o dinheiro 
da corrida no mesmo dia. "A moça chegava na porta da casa e descia e não voltava e o taxista batia na casa e dizia que uma moça tinha rodado com ele e tinha entrado no carro e não tinha pagado". Enquanto que na obra de Monteiro (2000), o taxista só volta para cobrar o dinheiro no dia seguinte

Entretanto, existe um consenso no que diz respeito ao final da história e ao dia em que esta acontece (o dia do aniversário da moça). Todos os entrevistados terminaram a história relatando que a família da moça mostrava a foto dela e contava que ela já havia falecido. A moradora da Pedreira, Rafaela Espíndola, relatou que "o taxista ia lá, mas aí ele via a foto dela na parede e a mãe dela dizia que ela já tinha morrido há algum tempo".

A história da "Moça do Táxi” mantém o sentido geral entre todos os entrevistados, variando apenas em pequenos detalhes. De acordo com Strauss isso se dá porque:

os mitos se transformam. Estas transformações, que se operam de uma variante a outra de um mesmo mito, de um mito a um outro mito, de uma sociedade a uma outra sociedade com referências aos mesmos mitos ou a mitos diferentes, afetam ora a armadura, ora o código, ora a mensagem do mito, mas sem que este deixe de existir como tal (STRAUSS,1993, p. 261).

Maria Carolina Feio, moradora do Umarizal há 15 anos, altera o nome da história, passando a chamá-la de "Menina do Táxi", e chega a se confundir sem saber direito em qual cemitério aconteceu a história, se no de Santa Izabel ou no da Soledad. Entretanto, somente esta entrevistada recordou do nome da Moça do Táxi: Josephina Conte.

Entre os informantes que relataram onde o taxista pegou a moça, houve um consenso, pois todos disseram ser em frente ao cemitério de Santa Izabel, divergindo dos relatos obtidos por Monteiro (2000), em que cada entrevistado relata um ponto da cidade diferente.

Quanto à procedência do conhecimento desses informantes da história, muitos relataram que familiares lhes contaram a história, como a Sra. Maria Auxiliadora dos Santos, do bairro do Umarizal, que escutou a história de sua avó e repassou para seus filhos. Outros disseram que a leram no livro de Monteiro (2000), como a informante do Umarizal, 
Juliana Silva, e João da Silva, do bairro da Pedreira, que conheceram a história lendo o livro desse autor, em suas escolas.

Ainda, a Sra. Maria Auxiliadora relata que escutou a história da "Moça do Táxi" em um programa de rádio:

Quando eu era criança, tinha um programa que passava na rádio que eu acho que era conversas de taxistas, e nele narravam como se estivesse acontecendo a história na hora, eu escutava de noite e tinha medo, mas hoje eu não acredito.

A segunda história mais relatada pelos informantes foi a da "Cobra Grande". Todos conheciam a existência da crença de uma cobra grande que nasceu e mora sob a cidade de Belém, bem como da crença de que, se essa cobra despertar, a cidade afundará. A moradora da Pedreira, Ana Luiza Cardoso Negrão, relata a crença:

Eu lembro que quando tava se aproximando do ano 2000, as pessoas acreditavam que o mundo ia acabar. Então se falava muito que Belém ia pro fundo do rio, porque a cobra grande ia acordar, e, assim que ela se mexesse, a cidade ia tremer até rachar, e aí ela inundaria

Surgiram algumas dúvidas a respeito de onde se situaria exatamente a "Cobra Grande". Todos souberam dizer que a cabeça ficava embaixo da Basílica, mas não sabiam onde ficava a cauda. A entrevistada Maria Carolina Feio relata o seguinte:

Eu ouvi alguma coisa na escola, mas nunca ninguém me detalhou. Até diziam pra mim: Tu não sabias que tem uma cobra grande embaixo de Belém? E que quando ela acordar Belém vai ser destruída?

Agora, eu não me lembro bem onde é que ela tava, parece que tem algo a ver com a Basilica. A cabeça parece que fica na Basilica e o rabo não sei onde fica, mas é só o que eu sei, nunca ninguém parou pra me contar direito.

Dessa forma, a depoente retrata a situação de muitos paraenses sobre o desconhecimento das histórias e das crenças que compõem a sua cultura, bem como sobre o desinteresse de contar/repassar essas histórias às novas gerações. 
Entre os informantes dos dois bairros, poucos souberam contar as lendas e os mitos existentes no bairro da Pedreira. Somente a história da "Matinta Perera" foi relatada, e isso por pessoas procedentes do interior do estado (onde a história é muito conhecida) ou por aquelas que comumente para lá viajavam.

Matinta Perera é uma história conhecida não somente pelos moradores dos bairros entrevistados, mas por toda a cidade de Belém. Trata-se de uma senhora que vira um pássaro, tal qual descreve Maués e Villacorta (2001), no livro Encantaria Brasileira. Nos relatos dos informantes, pôde-se perceber que a Matinta Perera do meio urbano ainda preserva a mesma essência do meio rural.

Somente os irmãos Jorge e Ana Carolina Barroso, moradores do bairro do Umarizal, souberam contar a história da Matinta Perera, fazendo alusão ao bairro da Pedreira. Ana Carolina relata:

Parece que era uma senhora, em uma rua simples na Pedreira, parece que ela era meio diferente, ela dava calafrios. Todo mundo achava, principalmente as crianças que ela era uma bruxa.

Parece que morava um pai e um filho numa casa e aí teve uma noite...que eles escutaram um meio que assobio e todo mundo falava que quando ouvisse um assobio muito forte era só falar: Matinta, volta manhã pra pegar o tabaco.

E um dia eles ouviram o assobio muito forte e ele falou Matinta Perera vem pegar o tabaco e eles deixaram o tabaco no quintal e tinha um pássaro parece, se eu não me engano ela era uma pássaro, que quando ele deixou o tabaco pra ela, ele viu um pássaro que se transformou na velha e ele ficou assustado em ver que aquilo era verdade, porque ele não acreditava no que o filho dizia.

A informante se lembrava muito pouco da história, inclusive não sabendo colocar em ordem os acontecimentos. Ao final de seu relato, ela pediu que lhe fosse contada a história para que ela pudesse lembrar.

Todos os outros, inclusive os moradores da Pedreira, contaram as histórias que ou vivenciaram no interior ou que lhe foram repassadas. A Sra. Maria Lúcia Santos, moradora do Umarizal, há 50 anos, conta que na infância ia para Vigia com o seu pai: 
Quando eu era criança em Vigia, as velhas assobiavam nas brechas das paredes, eu me tremia de medo, até botava papel nas brechas pra não ouvir o assobio da Matinta. Aí o pai sempre falava, ah vem buscar tabaco amanhã e a velha ia no outro dia buscar o rapé.

Os informantes tinham idades que variavam entre 23 e 60 anos, não tendo sido entrevistadas pessoas mais jovens por não conhecerem as histórias em questão. A Sra. Maria Auxiliadora atenta para o fato de que inclusive seus netos não conheciam as histórias, porque não se interessavam por conhecê-las, ressaltando que "as crianças de hoje não têm mais cultura, só querem a televisão e não gostam de ouvir essas histórias".

Os entrevistados eram pessoas de situações financeiras diferentes e, portanto, de visão cultural diferente. Os moradores do bairro do Umarizal, por apresentarem situação financeira superior à dos moradores do bairro da Pedreira, possuem uma visão cultural que mostra um paralelo entre a modernidade e o tradicional, demonstrando maior resistência em não somente não acreditar nas histórias de visagens e assombração, mas também em não quererem repassá-las aos seus filhos e amigos, por não acharem-nas importantes a ponto de terem de contá-las. Por sua vez, os jovens também não querem ouvi-las. Entretanto, a situação financeira não foi considerada um fator relevante para o conhecimento ou o não conhecimento das lendas e mitos de Belém.

Houve um consenso entre os entrevistados sobre a importância e a relevância destas histórias para o povo paraense. A Sra. Maria Auxiliadora acredita que "seria essencial para a cultura das crianças, para que essas conheçam um pouco mais sobre as nossas lendas e mitos, e também para que os outros conheçam a nossa cultura”.

Esse sentimento manifestado pela Sra. Maria Auxiliadora é também observado em uma parcela da população belenense, que acredita ser importante não dissociar o saber tradicional da transmissão cultural para que essas histórias, com o tempo, não venham a ser apagadas.

Ao perguntarmos sobre as histórias que os informantes não relatavam, a maioria nos pediu para que contássemos as que não conheciam, expondo desta forma, a curiosidade de muitos em conhecer mais sobre a sua própria cultura. 
Quanto à narrativa "Os gritos dos lenhadores da Pedreira", não foi possível encontrar nenhum morador que soubesse nos contar essa história. Somente alguns poucos, como a moradora Bruna Saraiva, lembravam que já haviam escutado há alguns anos algo sobre esta história, mas que atualmente não lembrava mais.

Esta narrativa foi mais uma, entre tantas outras, que foi apagada pela oralidade, visto que esta história foi relatada a Monteiro (2000), há algumas décadas, e atualmente nenhum dos moradores entrevistados soube narrá-la.

As lendas e mitos da cidade de Belém contêm, como exposto anteriormente, uma riqueza cultural que deve ser valorizada pela população, pois ela apresenta a identidade local com suas pluralidades e peculiaridades.

\section{Notas conclusivas}

Por meio das entrevistas realizadas, observou-se o interesse dos moradores da capital paraense em retomar o costume de contar histórias como parte do seu cotidiano, evitando que estas caiam em esquecimento, como foi o caso da história de visagem "O grito do lenhador", a qual foi extinta da memória de muitos moradores dos bairros Umarizal e Pedreira

A cultura regional tem seu espaço significativo à medida que a própria comunidade identifica e valoriza sua cultura. $\mathrm{O}$ não compartilhamento da cultura não pode ser entendido como meio de preservação cultural. A cultura se sustenta e sobrevive no contato com outras culturas, promovendo uma circularidade cultural, em que as trocas e as adaptações acontecem sem a eliminação de uma cultura pela outra. A valorização da cultura regional não pode ser feita por meio da sua colocação em uma redoma.

A utilização dos mitos e das lendas, como elemento para o turismo cultural de uma forma esquematizada, não apenas valorizará a identidade local, mas também possibilitará que esta atividade, economicamente, possa usar seu potencial para conservar e valorizar a cultura, aniquilando a ideia de que o turismo e o turista são inimigos da preservação cultural, passando a vê-los como possíveis aliados dessa preservação. 


\section{REFERÊNCIAS}

ARANTES, Antonio Augusto. O que é cultura popular. $14^{a}$ ed. São Paulo: Editora Brasiliense, 1990.

BELTRÃO, Otto di. Turismo: A indústria do Século 21. São Paulo: Editora Novo Século, 2001.

BERTOLLI FILHO, Cláudio.; GUARALDO, Tamara de Souza Brandão. Cultura Local, Turismo e Identidade: a ressignificação dos mitos em dois córregos, 2006. Disponível: < http://www.revista.inf.br/turismo04/ artigos/art04.pdf> . Acesso: 01/12/2008.

BRANDÃO, Carlos Rodrigues. O que é Folclore. $7^{a}$ ed. São Paulo. São Paulo: Editora Brasiliense, 1986.

CRUZ, Ernesto. Ruas de Belém: significado histórico de suas denominações. $2^{\mathrm{a}}$ ed. Belém: CEJUP, 992.

DAMATTA, Roberto. O que faz o Brasil, Brasil? Rio de Janeiro: Rocco, 1986.

ELIADE, Mircea. Mito e Realidade. São Paulo: Perspectiva, 1972.

FERREIRA, Aurélio Buarque de Holanda. Dicionário Aurélio básico da língua portuguesa. Rio de Janeiro: Editora Nova Fronteira, 1995.

FUNARI, Pedro Paulo; PINSKY, Jaime (Org.). Turismo e patrimônio cultural. $3^{a}$ ed. São Paulo: Editora Contexto, 2003.

GASTAL, Suzana (Org.). Turismo investigação e crítica. São Paulo: Contexto, 2002.

LARAIA, Roque de Barros. Cultura: um conceito antropológico. $11^{\mathrm{a}}$ Ed. Rio de Janeiro: Jorge Zahar Editor, 1997.

LEMOS, Carlos Antônio. O que é patrimônio histórico. 1ª ed. São Paulo: Editora Brasiliense, 1981.

LÉVI-STRAUSS, Claude. Antropologia estrutural dois. $4^{a}$ ed. Rio de Janeiro: Tempo Brasileiro, 1993.

LÉVI-STRAUSS, Claude. Antropologia estrutural. $6^{\mathrm{a}}$ ed. Rio de Janeiro: Tempo Brasileiro, 2003.

LÉVI-STRAUSS, Claude. O pensamento selvagem. São Paulo: Cia. Editora Nacional, 1976. 
MARCONI, Marina de Andrade; PRESOTTO, Zelia Maria Neves. Antropologia: uma introdução. $6^{a}$ ed. $2^{a}$ reimpressão. São Paulo: Atlas, 2006.

MARTINS, José Clerton de Oliveira. Identidade: percepção e contexto. In: MARTINS, José Clerton de Oliveira (Org.). Turismo, cultura e identidade. São Paulo: Roca, 2003.

MAUÉS, Raymundo Heraldo; VILLACORTA, Gisela Macambira. Pajelança e Encantaria amazônica In: PRANDI, Reginal (Org.). Encantaria Brasileira: o livro dos mestres, caboclos e encantados. Rio de Janeiro: Editora Pallas, 2001.

MELO, Luis Gonzaga de. Antropologia cultural: iniciação, teoria e temas. 13a ed. Petrópolis: Editora Vozes, 2007.

MENDES, Candido (Coord.). Pluralismo cultural, identidade e globalização. Rio de Janeiro: Record, 2001.

MONTEIRO, Walcyr. Visagens e Assombrações de Belém. $3^{a}$ Ed. Belém: Banco da Amazônia S.A., 2000.

MONTEJANO, Jordi Montaner. Estrutura do mercado turístico. $2^{\mathrm{a}}$ ed. São Paulo: Roca, 2001.

SÁ, Rosana Bignami Viana de. A imagem do Brasil no Turismo: construção, desafios e vantagem competitiva. São Paulo: Editora Aleph, 2002.

SANTOS, José Luiz dos. O que é Cultura. $14^{a}$ Ed. São Paulo: Editora Brasiliense, 1994.

SANTOS, Reinaldo Soares dos. O Encanto da Lagoa: o imaginário histórico-cultural como elemento propulsor para o Turismo Cultural na Lagoa Encantada. Dissertação de Mestrado em Cultura e Turismo. Bahia: Universidade Estadual de Santa Cruz, 2004.

SAVOLDI, Adiles. A reconstrução da italianidade no sul do estado de Santa Catarina. BANDUCCI JR, Álvaro; BARRETO, Margarita (Org.). Turismo e identidade local: uma visão antropológica. $2^{a}$ Ed. Campinas: Papirus, 2001.

VAZ, Gil Nuno. Marketing turístico: receptivo e emissivo. São Paulo: Editora Pioneira, 2002.

VER-O-PARA. Lendas e Mitos da Amazônia. Belém: VER Editora. 